\title{
Article \\ Granular Aggregates Based on Finely Dispersed Substandard Raw Materials
}

\author{
Valery Lesovik $^{1,2}$, Liliya Zagorodnyuk ${ }^{1}$, Vladislav Ryzhikh ${ }^{1} \mathbb{D}$, Ruslan Lesovik $^{1}$, Roman Fediuk ${ }^{3, * \mathbb{D}}$, \\ Nikolai Vatin ${ }^{4}$ (D) and Maria Karelina ${ }^{5}$
}

check for

updates

Citation: Lesovik, V.; Zagorodnyuk,

L.; Ryzhikh, V.; Lesovik, R.; Fediuk,

R.; Vatin, N.; Karelina, M. Granular

Aggregates Based on Finely

Dispersed Substandard Raw

Materials. Crystals 2021, 11, 369.

https: / / doi.org/10.3390/cryst

11040369

Academic Editor:

Yurii Barabanshchikov

Received: 9 March 2021

Accepted: 30 March 2021

Published: 31 March 2021

Publisher's Note: MDPI stays neutral with regard to jurisdictional claims in published maps and institutional affiliations.

Copyright: (C) 2021 by the authors. Licensee MDPI, Basel, Switzerland. This article is an open access article distributed under the terms and conditions of the Creative Commons Attribution (CC BY) license (https:/ / creativecommons.org/licenses/by/ $4.0 /)$.
1 Department of Building Materials Science, Products and Structures, Belgorod State Technological University Named after V.G. Shukhov, 308012 Belgorod, Russia; naukavs@mail.ru (V.L.); 1hz47@mail.ru (L.Z.); ryzhikh.vlad@mail.ru (V.R.); ruslan_lesovik@mail.ru (R.L.)

2 Research Institute of Building Physics of the Russian Academy of Architecture and Building Sciences, 127238 Moscow, Russia

3 Polytechnic Institute, Far Eastern Federal University, 690922 Vladivostok, Russia

4 Institute of Civil Engineering, Peter the Great St. Petersburg Polytechnic University, 195251 St. Petersburg, Russia; vatin@mail.ru

5 Department of Machine Parts and Theory of Mechanisms, Moscow Automobile and Road Construction University, 125319 Moscow, Russia; Karelinamu@mail.ru

* Correspondence: fedyuk.rs@dvfu.ru

\begin{abstract}
It is necessary to solve the ecological problems of regions where there is large-tonnage storage of various finely dispersed materials, including technogenic ones. This article presents the results of an investigation into the possible use of substandard dispersed quartz sands to obtain effective granular aggregates, with the purpose of putting them to use in mortars and concrete. The study used standard and original experimental research methods related to the analysis and preparation of raw materials, technological tests, and the study of the properties of finished composites. Investigations were carried out to obtain composite binders in the component composition of which the use of different ratios of Portland cement and substandard quartz sands prepared in a vortex jet mill was envisaged. It was found that the obtained composite binders had high physical and mechanical characteristics, which was due to the high specific surface area and hydration activity. On the basis of composite binders and finely dispersed quartz sands (fineness from $\leq 0.16 \mathrm{~mm}$ to $1 \mathrm{~mm}$ ), the granulation of mixtures of 36 types of component compositions was performed. The developed compositions of granular aggregates (GAs) showed the possibility of obtaining them with sufficiently high strength values in cement stone. The studies carried out make it possible to recommend finely dispersed substandard and technogenic materials for the production of GAs, which would ensure the economy of binding materials as well as contribute to the reuse of large-tonnage waste of ferrous and nonferrous metallurgy and the chemical and mining industries.
\end{abstract}

Keywords: granulation; granular aggregates; composite binders; substandard quartz sands; manmade waste

\section{Introduction}

Currently, a significant portion of research work in the field of construction is aimed at studying and developing new environmentally friendly building materials with strong economic effects [1,2]. Saving material, energy, and financial resources, as well as improving the construction industry, are priority tasks of scientists around the world [3,4].

The shortage of various building materials in certain territories is a big problem for the construction industry [5,6]. Due to the lack of building materials, construction companies, mining companies and other enterprises are forced to use local and man-made raw materials for production. The use of a local raw materials construction cluster does not always allow for environmentally and economically beneficial construction $[7,8]$. 
The production of concretes and mortars in different regions implies the use of individually selected raw materials in composite compositions, as a result of which quality may suffer and degradation of physical and mechanical characteristics is possible $[9,10]$. There are currently a number of scientific studies focused on the use of industrial waste in composite compositions and the selection of components in order to increase environmental safety and achieve optimal physical, mechanical, and technological characteristics of concretes and mortars; developments are underway to create composite binders with improved economic indicators, contributing to the growth of energy and financial resources for construction production [11,12]. It should be noted that developments are also underway to create concretes using recycled concrete aggregates (waste from the demolition of buildings and structures). Scientific research has shown the promise of using secondary resources to replace the volume of binders $[11,13]$.

There is systematic overexpenditure on expensive binders during the preparation of cement-sand mortars for the construction of facilities or backfill mixtures for mining workings $[13,14]$. This overconsumption of binders is justified by the irrational use of large and small aggregates in composite compositions, as well as by the heterogeneity of materials and their dispersion. The lack of research on the selection of the component composition of raw mixtures and the mathematical modeling for specific objects determines the size of the loss of investors $[15,16]$.

As practice shows, under modern conditions at concrete mixing plants, the production of concrete with rationally selected small and coarse aggregates - the use of which increases the density of mixes, reduces the consumption of binders and reduces the cost of production-is a growing priority. The lack of coarse natural aggregates in different parts of the world is a problem $[17,18]$. The search for new coarse aggregates requires the extraction of additional natural resources, the use of which leads to a violation of the natural ecological balance $[19,20]$. To solve the problems associated with the normalization of the environmental situation-reducing the cost of concretes and increasing their strength-it has been proposed that compacted (granular) aggregates should be developed on the basis of fine natural quartz sands, which contribute to the intensification of the production process [21,22].

Today, the construction industry does not extensively use fine sands in production technologies, although there are huge reserves across the territories of the globe $[23,24]$. Since quartz sands with fractions $\leq 1 \mathrm{~mm}$ are not regulated for the construction industry, their storage reserves increase every year, as a result of which foci for dust formation appear, weathering of raw materials occur, dust storms form, and the ecological situation worsens $[25,26]$. Creation of effective granular aggregates with sufficient physical and mechanical properties based on small quartz sands can reduce the consumption of energy resources during production and reduce the consumption of expensive binders, thereby helping to reduce the negative technogenic burden on the environment in the production of Portland cement [27,28].

The modern building materials industry maintains large reserves for intensifying technological processes based on agglomeration [29,30]. Any kind of agglomeration leads to the approach of particles, an increase in interparticle contacts directly or through a binder. Agglomeration processes for fine aggregates and powdered materials are widely used in the production of building materials and mineral fertilizers, mining and other fields.

An examination of previous studies from the literature showed that the use of agglomeration to create aggregates is often deployed in the preparation of various composites, favorably affecting energy efficiency and the environmental friendliness of production [31-35]. Some studies concerning lightweight concrete filled with cold-bonded fly ash with a low thermal conductivity coefficient were recently carried out at the St. Petersburg Polytechnic University [36,37]. Furthermore, in order to increase the physical and mechanical properties of composites, the development of cement-sand mortars with granular aggregates is being carried out with preliminary mechanical treatment of binding components in grinding units [38-41]. 
The problem of obtaining aggregates that can increase the strength characteristics of concretes and mortars whilst ensuring that they can be sold in almost any territory of the world, as well as having the potential for environmentally friendly uses and savings in resources, is an urgent one.

\section{Materials and Methods}

\subsection{Materials and Instruments}

The materials used in this study were quartz sand and CEM I 42.5 R Portland cement. Quartz sand with a fineness of $\leq 0.16 \mathrm{~mm}$ to $1 \mathrm{~mm}$ was used.

The grinding of composite binders (mixture of Portland cement with quartz sand) was carried out using a VSM-01 vortex jet mill, capable of increasing the speed of the vortex in the grinding chamber to supersonic units and capturing ultrafine particles of ground raw materials thanks to an electronic filter device. Sifting of quartz sand was carried out using laboratory sieves. Granulometric studies of composite binders were performed with a FR ITSCH Analysette 22 NanoTec device. The granulation of quartz sand was carried out using an automatic Mystery MGM-3000 screw installation with a power of $3000 \mathrm{~W}$ and the possibility of changing the screw rotation speed. The strength tests of the cube samples were carried out with a PGM-50MG4 hydraulic press in compliance with the requirements of the Russian National Standard GOST 10180-2012. Microscopic images of the chips of the cube samples were made with a TESCAN MIRA 3 LMU high-resolution electron microscope.

\subsection{Research Methods}

\subsubsection{Obtaining Composite Binders}

To obtain composite binders, the following studies were carried out. Using an ARL 9900 WorkStation series X-ray fluorescence spectrometer, the mineralogical composition of the Portland cement was determined, as indicated in Table 1.

Table 1. Mineralogical composition of the CEM I 42.5 R Portland cement.

\begin{tabular}{cc}
\hline Mineral Type & Content, $\%$ \\
\hline Tricalcium silicate $\left(\mathrm{C}_{3} \mathrm{~S}\right)$ & $59.0 \pm 2$ \\
Dicalcium silicate $\left(\mathrm{C}_{2} \mathrm{~S}\right)$ & $18.8 \pm 2$ \\
Tricalcium aluminate $\left(\mathrm{C}_{3} \mathrm{~A}\right)$ & $7 \pm 0.2$ \\
Tetracalcium alumoferite $\left(\mathrm{C}_{4} \mathrm{AF}\right)$ & $13.1 \pm 0.25$ \\
\hline
\end{tabular}

Three pieces of CEM I 42.5 R Portland cement weighing $5 \mathrm{~kg}$ each were selected as representative samples. Quartz sand with a fraction of $\leq 1 \mathrm{~mm}$ in a certain volume was successively added to each sample, followed by stirring. The composite binders (CBs) with CEM I $42.5 \mathrm{R}$ and quartz sand are presented in Table 2.

Table 2. Percentage addition of quartz sand to CEM I 42.5 R Portland cement.

\begin{tabular}{cc}
\hline Mix ID & Decoding \\
\hline CEM & CEM I 42.5 R \\
CB-1 & CEM I 42.5 R + 10\% quartz sand \\
CB-2 & CEM I 42.5 R + 20\% quartz sand \\
CB-3 & CEM I 42.5 R + 30\% quartz sand \\
\hline
\end{tabular}

Furthermore, the obtained composite compositions were ground in a VSM-01vortex jet mill. The purpose of grinding the composite binder was to increase the dispersion, specific surface area and activation of Portland cement and aggregate particles. 


\subsubsection{Aggregate Granulation Technique}

The aggregate granulation was carried out using the methods of mechanical mixing, pressing and extrusion. Previously, for accuracy and completeness of research, the quartz sand was divided into three main fractions by means of laboratory sieves: $\leq 0.16 \mathrm{~mm}$, $0.315 \mathrm{~mm}$ and $0.63 \mathrm{~mm}$. Next, each fraction of quartz sand was mixed in a certain percentage with the prepared composite binders, as indicated in Table 2. The percentages of composite binders added were $5 \%, 10 \%$, and $15 \%$ of the total weight of the mixed material. During the experiment, 36 formulations of granular aggregates (GAs) were developed. Table 3 shows the formulations of granular aggregates with the designation of the percentage of addition of binders to the component compositions.

Table 3. Granular aggregate recipes.

\begin{tabular}{ccccc}
\hline Binder Type & CEM & CB-1 & CB-2 & CB-3 \\
\hline \multirow{3}{*}{$0.16 \mathrm{~mm}$} & $0.16+5 \%$ CEM & $0.16+5 \%$ CB-1 & $0.16+5 \%$ CB-2 & $0.16+5 \%$ CB-3 \\
& $0.16+10 \%$ CEM & $0.16+10 \%$ CB-1 & $0.16+10 \%$ CB-2 & $0.16+10 \%$ CB-3 \\
& $0.16+15 \%$ CEM & $0.16+15 \%$ CB- 1 & $0.16+15 \%$ CB-2 & $0.16+15 \%$ CB-3 \\
\hline \multirow{3}{*}{$0.315 \mathrm{~mm}$} & $0.315+5 \%$ CEM & $0.315+5 \%$ CB-1 & $0.315+5 \%$ CB-2 & $0.315+5 \%$ CB-3 \\
& $0.315+10 \%$ CEM & $0.315+10 \%$ CB-1 & $0.315+10 \%$ CB-2 & $0.315+10 \%$ CB-3 \\
& $0.315+15 \%$ CEM & $0.315+15 \%$ CB-1 & $0.315+15 \%$ CB-2 & $0.315+15 \%$ CB-3 \\
\hline \multirow{3}{*}{$0.63 \mathrm{~mm}$} & $0.63+5 \%$ CEM & $0.63+5 \%$ CB-1 & $0.63+5 \%$ CB-2 & $0.63+5 \%$ CB-3 \\
& $0.63+10 \%$ CEM & $0.63+10 \%$ CB- 1 & $0.63+10 \%$ CB-2 & $0.63+10 \%$ CB-3 \\
& $0.63+15 \%$ CEM & $0.63+15 \%$ CB- 1 & $0.63+15 \%$ CB-2 & $0.63+15 \%$ CB-3 \\
\hline
\end{tabular}

In the manufacture of granular aggregates with different contents of composite binders, water was introduced to ensure the formation of granules and subsequent hardening. The water-binder ratio in the component compositions of granular aggregates was equal to $3 \%$ for the addition of a composite binder, whilst $10 \%$ was equal to a ratio of 1.7 and $15 \%$ to 1.3 .

Aggregate granulation was carried out using extrusion molding technology with preliminary compression of the composite material. In the process of increasing the rotation speed of the screw of the auger installation, the optimally water-saturated cementsand mixture was additionally pressed and underwent the extrusion process. After being squeezed out of the grating (coarse-cut plate), GAs of cylindrical shape were separated by gravity and fell onto a moving surface pre-moistened with distilled water. After that, within 28 days, the GAs gained strength in humid-air conditions. A general view of the granular aggregates based on quartz sands of different fractions is provided in Figure 1.

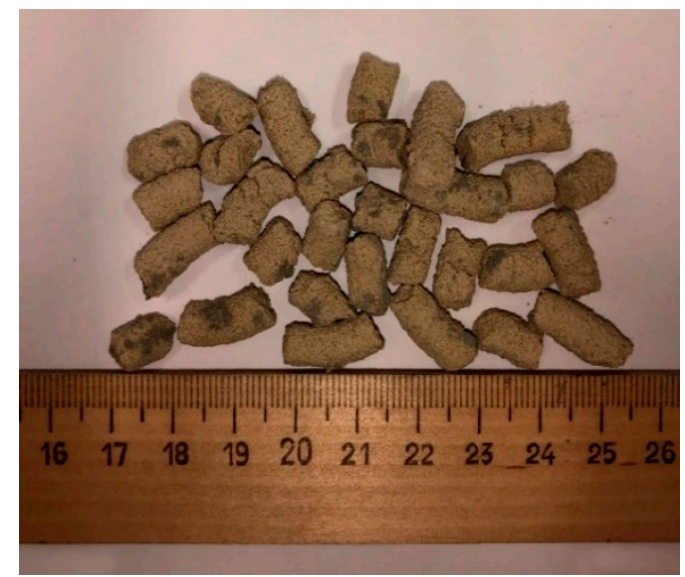

(a)

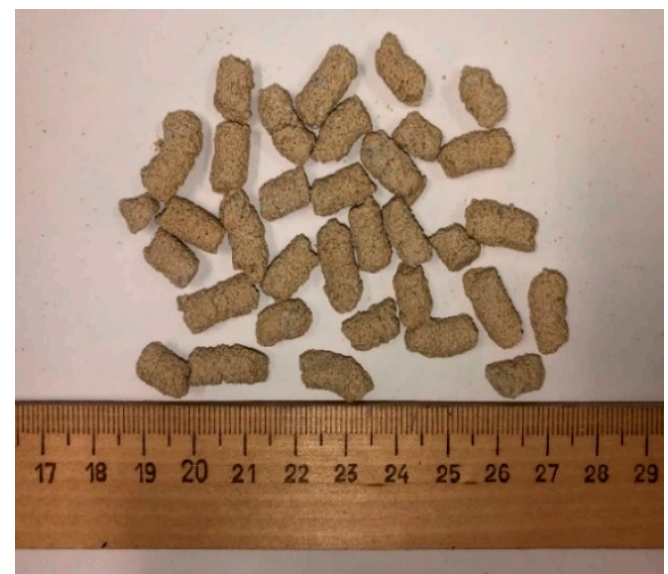

(b)

Figure 1. Cont. 


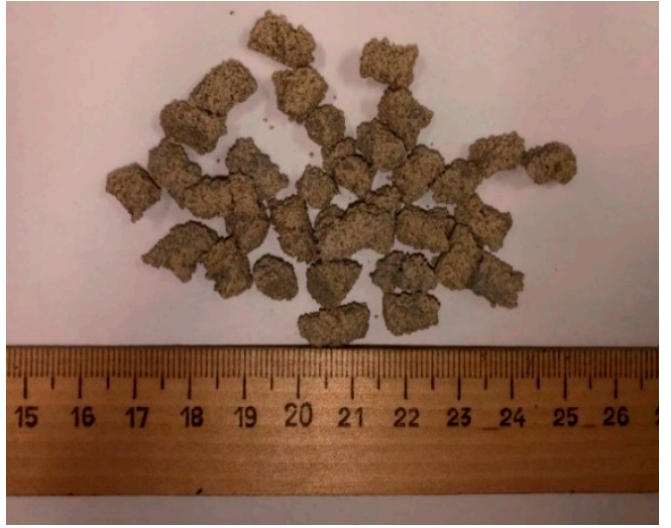

(c)

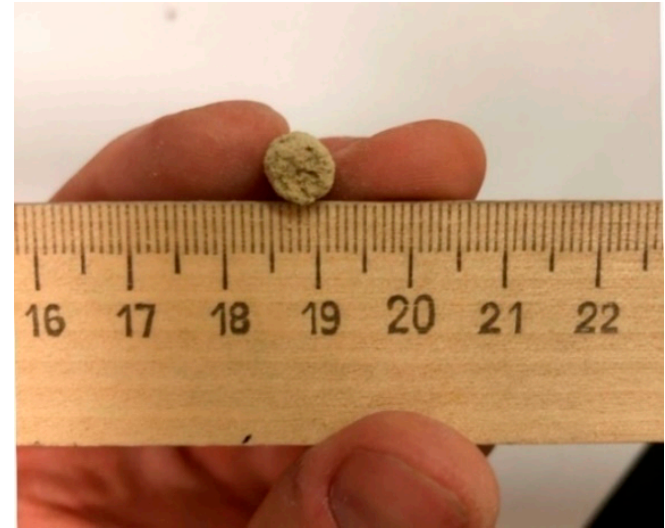

(d)

Figure 1. General view with linear dimensional units (mm) of granular aggregates (GAs). (a) GAs based on quartz sand with a $0.16 \mathrm{~mm}$ fraction and addition of $15 \%$ composite binder (CB)-2; (b) GAs based on quartz sand with a fraction of $0.315 \mathrm{~mm}$ and addition of $15 \%$ CB-2; (c) GAs based on quartz sand with a fraction of $0.63 \mathrm{~mm}$ and addition of $15 \% \mathrm{CB}-2$; (d) measuring the diameter of granular aggregates.

The process of preparing GAs is a rather meticulous process that requires frequent and thorough washing of the elements and assemblies of the screw installation.

\subsubsection{Formation and Testing of Sample Cubes}

In order to study the strength characteristics of granular aggregates under laboratory conditions, the samples were molded into cubes with dimensions of $3 \times 3 \times 3 \mathrm{~cm}$. The composition for molding deployed the following percentages of components: $40 \%$ CEM I; $40 \%$ GA; $20 \%$ water. The porosity of the structure of the composite mixture and the water-cement ratio had a significant effect on the strength indicators of the cubes. To achieve the densest structure of the mortar, the molds were shaken on a laboratory shaking table for 2-3 min.

In the course of the research, 108 sample cubes were formed based on 36 recipes. For a more complete comparative analysis, three cube samples of $3 \times 3 \times 3 \mathrm{~cm}$ were additionally molded with the following composition: $66.67 \%$ CEM and $33.33 \%$ water. The molding of the cube samples was carried out in such a way that the GAs in all steel forms occupied the maximum volume. The process for increasing the strength of the cube specimens in humid-air conditions was carried out for 28 days.

Microstructure studies were carried out using a TESCAN MIRA 3 LMU high-resolution electron microscope, with which photographs of the contact layers of the cement mortar and cement paste were taken.

\section{Results}

Granulometric characteristics of the composite binders obtained in the VSM-01 and unmilled Portland cement are shown in Figure 2. The particle distribution curve of Portland cement demonstrates standard granulometric characteristics for CEM and shows a distribution of particles from 0.1 to $100 \mu \mathrm{m}$, with a specific surface area of $330 \mathrm{~m}^{2} / \mathrm{kg}$. Analyzing the experimental curves of particle size distribution, it should be noted that ground composite binders (CB-1, CB-2, CB-3) were distinguished by increased dispersion characteristics, with a particle distribution of 0.1 to $30 \mu \mathrm{m}$. It was found that when composite binders were milled, the specific surface area increased by two or more times; it was $652 \mathrm{~m}^{2} / \mathrm{kg}$ for CB-1, $631 \mathrm{~m}^{2} / \mathrm{kg}$ for CB-2, and $606 \mathrm{~m}^{2} / \mathrm{kg}$ for CB-3. The reduction of the specific surface area of ground binders was proportional to the content of quartz sand in the component composition of the composite binders. 


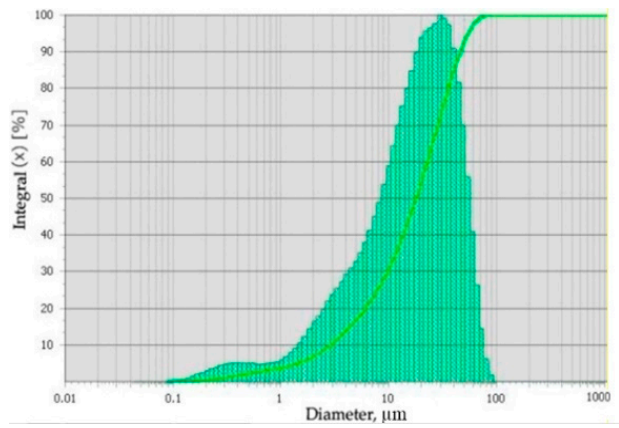

(a)

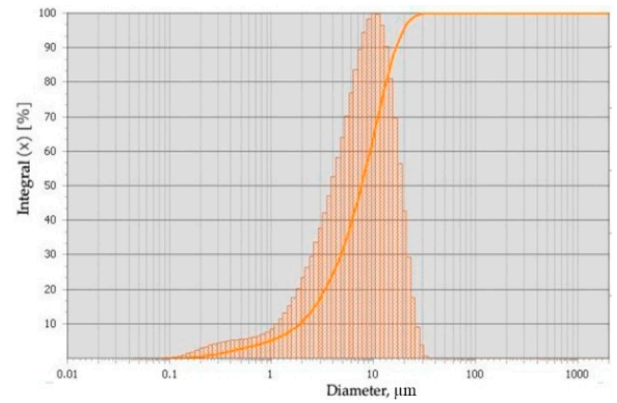

(c)

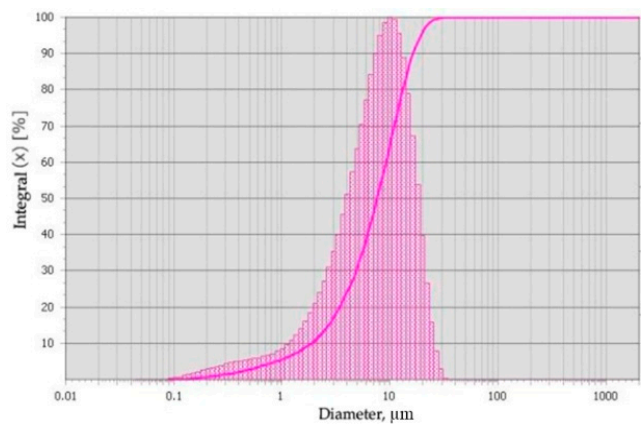

(b)

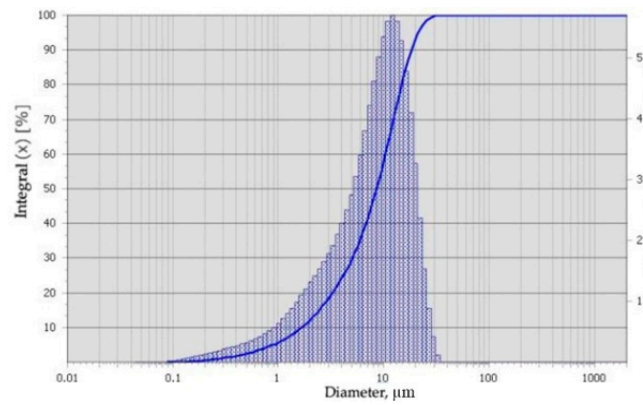

(d)

Figure 2. Granulometric composition of binders: (a) CEM; (b) composite binder (CB)-1; (c) CB-2; (d) CB-3.

In order to study the physicomechanical properties of hydrated binders with a PGM50MG4 hydraulic press, tests of the compressive strength of $3 \times 3 \times 3 \mathrm{~cm}$ cubes molded from Portland cement and composite binders CB-1, CB-2, and CB-3 with a water-cement ratio of 0.4 were undertaken. The test results for the sample cubes are shown in Table 4 .

Table 4. Results of compressive strength tests of sample cubes made of Portland cement and ground composite binders.

\begin{tabular}{ccccccc}
\hline \multirow{2}{*}{ Binder Type } & \multirow{2}{*}{$\begin{array}{c}\text { Standard } \\
\text { Consistency, } \%\end{array}$} & $\begin{array}{c}\text { Amount of } \\
\text { Water, } \mathbf{~ m L}\end{array}$ & \multicolumn{2}{c}{ Setting Time, min } & \multicolumn{2}{c}{ Compressive Strength, MPa } \\
\cline { 4 - 7 } & 26 & 104 & Start & End & After 3 Days & After 28 Days \\
\hline CEM & 37 & 148 & 144 & 258 & 21.3 & 52.4 \\
CB-1 & 43 & 172 & 110 & 224 & 28.3 & 69.5 \\
CB-2 & 48 & 192 & 122 & 235 & 26.2 & 67.4 \\
CB-3 & & & & & 24.0 & 61.7 \\
\hline
\end{tabular}

Furthermore, based on the 36 formulations developed, aggregates were granulated using quartz sand with different dispersions and binding compositions. Granular aggregates with different contents of binders, having gained strength over 28 days, formed non-identical adhesive structures and had different levels of porosity and strength. Obviously, with an increase in the fineness of quartz sand from $\leq 0.16 \mathrm{~mm}$ to $0.63 \mathrm{~mm}$, the porosity of GAs increases; therefore, when a common composite system with different types of GAs is created, the physical and mechanical characteristics of the samples differ.

After the technological processes of molding and increasing the strength of the cube specimens with GAs and Portland cement, laboratory tests of the cube specimens under compression were carried out using a PGM-50G4 hydraulic press. The cubes were formed from cement paste based on CEM and distilled water with a water-cement ratio of 0.5. As a result of testing the cube samples, the numerical values for the compressive strength were obtained, as recorded in Table 5. 
Table 5. Results of compressive strength tests for sample cubes made of Portland cement and GAs.

\begin{tabular}{|c|c|c|c|c|}
\hline \multirow{2}{*}{$\begin{array}{l}\text { Composition } \\
\text { Number }\end{array}$} & \multirow{2}{*}{ Mix ID } & \multicolumn{3}{|c|}{ Compressive Strength, $\mathrm{MPa}$} \\
\hline & & Cube 1 & Cube 2 & Cube 3 \\
\hline 1 & CEM & 38.65 & 34.64 & 35.27 \\
\hline 2 & $0.16+5 \% \mathrm{CEM}$ & 14.51 & 8.77 & 13.30 \\
\hline 3 & $0.16+10 \%$ CEM & 22.12 & 15.65 & 18.93 \\
\hline 4 & $0.16+15 \%$ CEM & 17.43 & 18.26 & 18.12 \\
\hline 5 & $0.315+5 \%$ CEM & 6.86 & 10.85 & 9.66 \\
\hline 6 & $0.315+10 \%$ CEM & 17.93 & 21.57 & 19.84 \\
\hline 7 & $0.315+15 \%$ CEM & 14.69 & 17.98 & 16.34 \\
\hline 8 & $0.63+5 \%$ CEM & 11.23 & 13.96 & 14.32 \\
\hline 9 & $0.63+10 \%$ CEM & 22.57 & 16.12 & 18.65 \\
\hline 10 & $0.63+15 \%$ CEM & 19.33 & 22.80 & 16.34 \\
\hline 11 & $0.16+5 \% \mathrm{CB}-1$ & 8.85 & 9.54 & 7.47 \\
\hline 12 & $0.16+10 \%$ CB-1 & 19.35 & 18.18 & 20.88 \\
\hline 13 & $0.16+15 \%$ CB-1 & 14.44 & 15.42 & 19.09 \\
\hline 14 & $0.315+5 \%$ CB-1 & 13.43 & 16.31 & 15.02 \\
\hline 15 & $0.315+10 \%$ CB-1 & 24.53 & 26.52 & 24.18 \\
\hline 16 & $0.315+15 \%$ CB-1 & 20.98 & 21.80 & 21.30 \\
\hline 17 & $0.63+5 \%$ CB-1 & 15.13 & 22.62 & 18.21 \\
\hline 18 & $0.63+10 \%$ CB-1 & 24.53 & 22.13 & 19.61 \\
\hline 19 & $0.63+15 \%$ CB-1 & 23.67 & 26.32 & 25.70 \\
\hline 20 & $0.16+5 \% \mathrm{~KB}-2$ & 10.94 & 16.29 & 14.05 \\
\hline 21 & $0.16+10 \%$ CB -2 & 19.52 & 21.53 & 21.44 \\
\hline 22 & $0.16+15 \% \mathrm{~KB}-2$ & 22.88 & 23.38 & 23.11 \\
\hline 23 & $0.315+5 \%$ CB-2 & 12.35 & 16.32 & 15.09 \\
\hline 24 & $0.315+10 \%$ CB- 2 & 18.32 & 17.33 & 19.49 \\
\hline 25 & $0.315+15 \% \mathrm{~KB}-2$ & 19.15 & 19.02 & 18.87 \\
\hline 26 & $0.63+5 \%$ CB-2 & 21.35 & 23.58 & 20.04 \\
\hline 27 & $0.63+10 \%$ CB-2 & 34.22 & 31.93 & 32.36 \\
\hline 28 & $0.63+15 \%$ CB-2 & 34.34 & 34.50 & 32.61 \\
\hline 29 & $0.16+5 \%$ CB-3 & 16.33 & 14.65 & 15.27 \\
\hline 30 & $0.16+10 \%$ CB-3 & 15.32 & 14.61 & 15.32 \\
\hline 31 & $0.16+15 \%$ CB-3 & 23.14 & 21.05 & 19.43 \\
\hline 32 & $0.315+5 \%$ CB -3 & 19.09 & 20.45 & 21.38 \\
\hline 33 & $0.315+10 \%$ CB-3 & 18.74 & 17.35 & 19.01 \\
\hline 34 & $0.315+15 \%$ CB-3 & 27.02 & 26.57 & 25.33 \\
\hline 35 & $0.63+5 \%$ CB-3 & 19.74 & 20.14 & 22.06 \\
\hline 36 & $0.63+10 \%$ CB-3 & 24.32 & 24.46 & 22.32 \\
\hline 37 & $0.63+15 \%$ CB-3 & 28.38 & 27.11 & 29.59 \\
\hline
\end{tabular}

The results of laboratory tests showed that the GA content in the composition of mortars decreased the strength of the cubic specimens. However, we noticed that samples with GAs using composite binders and quartz sands showed higher strength indicators than samples with GAs based on CEM. This fact can be explained by the high hydration potential and fine grinding of the binding compositions.

Table 5 shows that there was an increase in the compressive strength of samples with GAs using composite binders with an increase in the size of quartz sand from $\leq 0.16$ to $0.63 \mathrm{~mm}$. This regularity was determined by the physicomechanical and physicochemical properties of the aggregates and composite binders, on which the strength, porosity, and the number of capillary pores of GAs depend.

It should be noted that the formation of the densest structures in the composites and the achievement of the maximum physicomechanical parameters for the sample cubes with grain boundaries is achievable only with an optimal ratio for the porosity of the system, the size of the contact areas and the strength of each individual grain of the grain boundaries. 
An important feature in the agglomeration of agglomerates is the creation of an optimized dimension for the contact layers of the interaction between the GA and the cement paste.

It is noteworthy that, when comparing the physical and mechanical characteristics of samples with GAs based on CB-1, CB-2, and CB-3, an increase in strength was observed with an increase in the content of quartz sand from $10 \%$ to $20 \%$, whilst an increase in the content of quartz sand to $30 \%$ led to indications of strength degradation.

The specimens with the mix IDs $0.63+10 \%$ CB-2 and $0.63+15 \%$ CB-2 deserve special attention; they had compressive strengths of, on average, $32.84 \mathrm{MPa}$ and $33.82 \mathrm{MPa}$, respectively. After carrying out a comparative analysis of the strength characteristics of the cement stone samples with mix IDs $0.63+10 \%$ CB-2 and $0.63+10 \%$ CB-2, it was necessary to confirm the significant economic effect and environmental feasibility that would result from using GAs based on quartz sand (dispersion of $0.63 \mathrm{~mm}$ ) with $10 \%$ or $15 \%$ CB-2 contents.

The chipped specimen cubes for mix IDs $0.63+10 \%$ CB- 2 and $0.63+15 \%$ CB- 2 are shown in Figure 3. Examination of the surfaces of the chipped samples revealed the features of destruction, characterized by a predominant rupture of filler grains. In the process of examining the destroyed samples, it was found that almost all the granules in the fault zones had the maximum diametric dimensions; therefore, the destruction occurred precisely at a radial distance from the contact zone of the granules and the cement paste. The destruction planes of each sample were different but directed in an identical direction to the distribution of granules in a cubic volume.

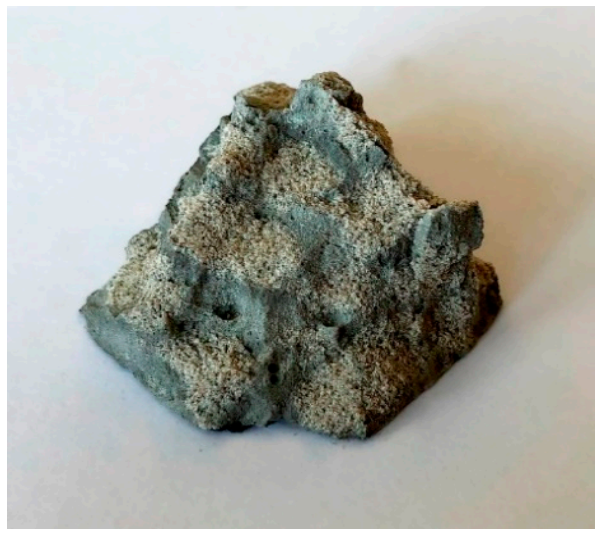

(a)

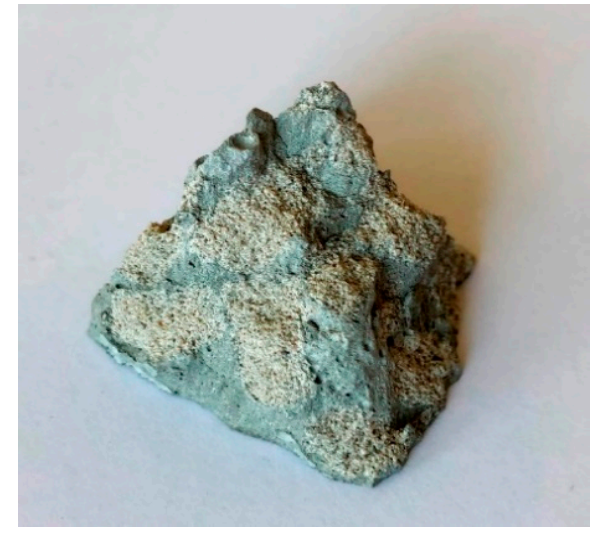

(b)

Figure 3. Appearance of the surfaces of chipped specimen cubes: (a) $0.63+10 \%$ CB-2 and (b) $0.63+$ $15 \%$ CB-2.

Investigation of the appearance of chipped sample cubes with promising compositions showed that the contact zones (layers) of the GAs and the cement paste had clearly visible conjugation lines. The reduced content of the composite binder in the GA composition led to an increase in the contact layers of the samples and an increase in the microstructural interaction of the Portland cement and aggregate particles.

Since the strength of the cubic specimens depended on the strength of the GAs and the dimension of the structural interaction of the cement paste and the GAs, a study of the microstructure of the destroyed surface of the $0.63+15 \%$ CB-2 specimen was carried out for the most characteristic areas of the contact layer (Figure 4) and for the isolated structure of the GA (Figure 5).

The microstructure of granular aggregates is characterized by the main structural components: crystalline intergrowth, tobermorite gel, incompletely hydrated cement grains, ground filler particles, and fine aggregate grains and pore space. 


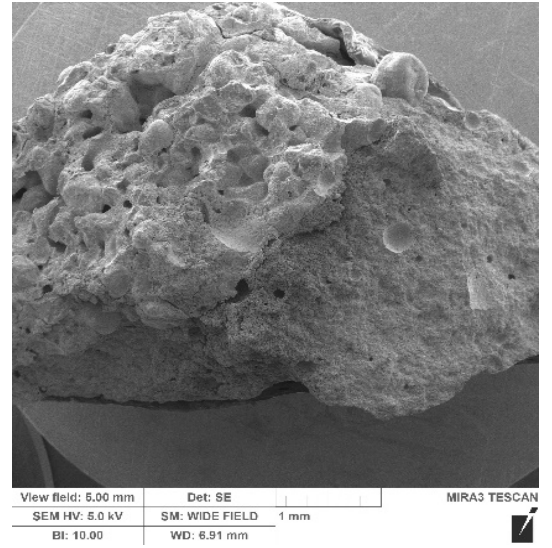

(a)

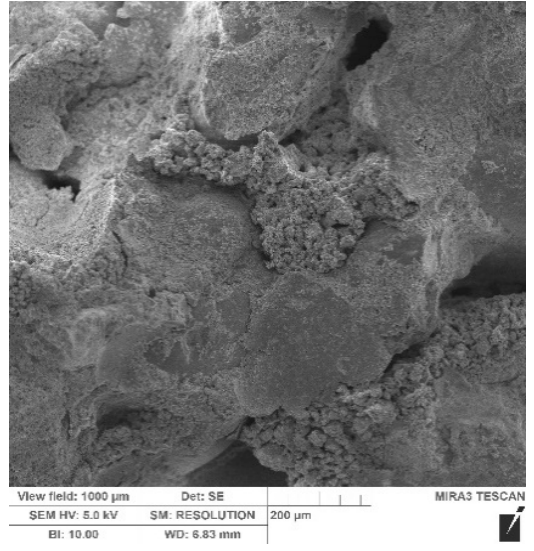

(b)

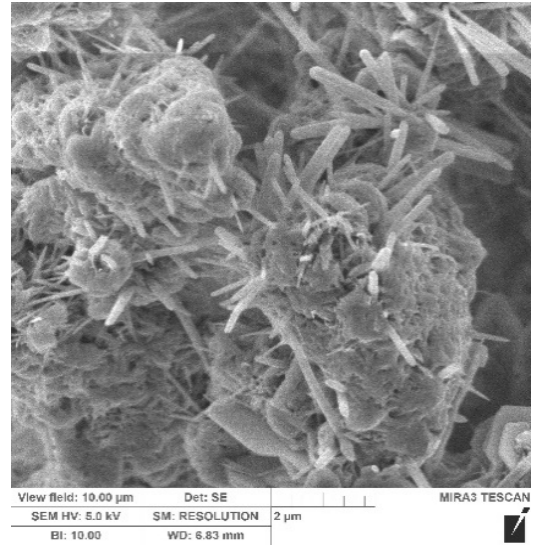

(c)

Figure 4. Microstructure of the cleavage surface of the $0.63+15 \%$ CB-2 specimen cube in the zone of the contact layer under various magnifications: (a) $5 \mathrm{~mm}$; (b) $1000 \mu \mathrm{m}$; (c) $10 \mu \mathrm{m}$.

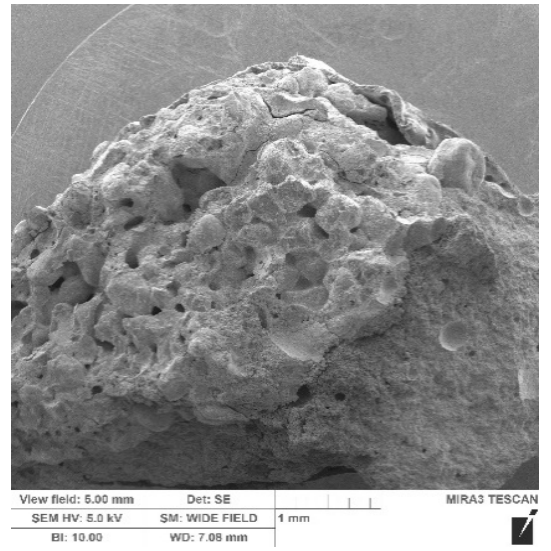

(a)

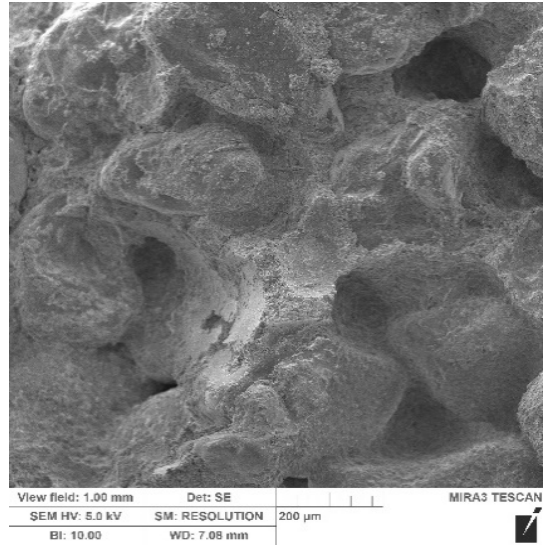

(b)

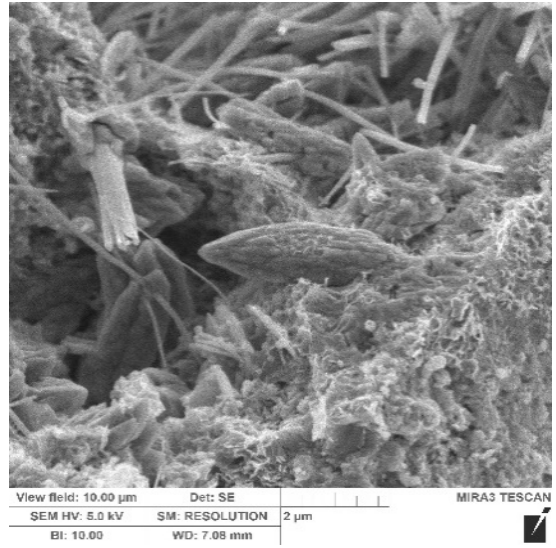

(c)

Figure 5. Microstructure of the cleavage surface of the $0.63+15 \%$ CB-2 specimen cube in the area of the isolated GA structure under various magnifications: (a) $5 \mathrm{~mm}$; (b) $1000 \mu \mathrm{m}$; (c) $10 \mu \mathrm{m}$.

The SEM images in Figure 4 ( $5 \mathrm{~mm}$ and $1000 \mu \mathrm{m}$ magnifications) clearly show the uniformly granular structure of the fractures of the samples. The presence of an insignificant number of pores with dimensions of 0.05 to $0.5 \mathrm{~mm}$ was noted. When the SEM image was enlarged to a viewing area of $10 \mu \mathrm{m}$, it was found that the structure of the contact zone was characterized by the presence of individual block aggregates formed by chaotically oriented flake-needle polycrystals. The overgrowth of filler grains with new crystalline formations was established, which indicated the development of a dense structure for the contact layer, the formation of which is a prerequisite for creating composites of high strength. The development of a differently oriented finely dispersed crystal structure, which forms bulk crystalline intergrowths, was clearly visible. A dense overgrowth of pores was noted, while the nucleation of initial small crystals along with already formed crystals was noted on the filler substrates, which indicated an active course in the internal physicochemical processes. Thus, the high density of germination of calcium hydrosilicates provides high strength to the contact zone and the system as a whole.

The SEM images in Figure 5 ( $5 \mathrm{~mm}$ and $1000 \mu \mathrm{m}$ magnifications) indicate that each particle of quartz sand in the GA was enveloped in an uneven layer of hydrated composite binder. The total mass contained a significant number of pores with sizes from $200 \mu \mathrm{m}$ to $0.6 \mathrm{~mm}$, distributed throughout the volume. An SEM image at a magnification of $10 \mu \mathrm{m}$ (Figure 5c) clearly shows that the interfacial transition zones inside the GA coalesced due 
to the presence of a composite binder. A significant amount of incipient finely dispersed crystals were found on the surface of the quartz sand particles, indicating the further progress of hydration processes and the gain in strength of the composite. Finely dispersed flaky polycrystals were formed on the filler particles of the interfacial transition zone, increasing the density of the structure of the entire system.

The study of the microstructure confirmed that the rational use of highly dispersed quartz sands contributes to both increasing the economic efficiency of manufacturing building materials, thus expanding the range and reducing the material consumption of manufactured products without deteriorating their quality, and increasing the use of substandard raw materials and thus preserving natural resources.

\section{Discussion}

Analyzing the results of the experiments, it should be noted that the proposed and developed method of agglomeration of finely dispersed quartz sands made it possible to obtain effective granular cylindrical aggregates with a diameter of $5 \mathrm{~mm}$ and a height of $10-12 \mathrm{~mm}$. Using the above methods, it is possible, by changing the parameters of the screw installation, to form GAs of required sizes and volumes, in accordance with the tasks and areas of use.

Depending on the purpose of the granular aggregates, the component compositions can be varied, e.g., by using Portland cement as the binders, composite binders based on Portland cement, finely ground cements, waterproof gypsum binders, and so on.

Using different natural or man-made raw materials as aggregates, it is possible to obtain various raw materials for the production of granular aggregates. The granular aggregates developed with the following compositions are of particular interest for their potential uses in construction production:

- $\quad$ the first GA composition, based on quartz sand with a fraction of $0.63 \mathrm{~mm}(90 \%$ of the volume of the composition) and the addition of $10 \%$ (of the volume of the composition) composite binders, prepared using $80 \%$ Portland cement and $20 \%$ quartz sand;

- $\quad$ the second GA composition, based on quartz sand with a fraction of $0.63 \mathrm{~mm}$ ( $85 \%$ of the volume of the composition) and the addition of $15 \%$ (of the volume of the composition) composite binders, prepared using $80 \%$ Portland cement and $20 \%$ quartz sand.

The given compositions for the GAs demonstrated the fundamental possibility of obtaining rather high strength indicators in cement stone. The results obtained make it possible to recommend the use of finely dispersed substandard and technogenic materials for the production of GAs, which will contribute to saving binders and the reuse of largetonnage waste from ferrous and nonferrous metallurgy and from the chemical and mining industries.

The question of using organic additives to impart specific functional properties to GAs-in particular, density, porosity, water absorption, and frost resistance-deserves attention in future studies.

When designing granular aggregates, it is necessary to study issues related to their operational loads and their service conditions, taking into account the presence of various aggressive media and their reliability and durability.

Considering that natural resources are decreasing on the planet, it is necessary to expand research on the use of substandard raw materials and man-made products to create artificial granular aggregates.

Examining the compressive strength of the obtained "cement-GA" composites, we found that they had a compressive strength 15-20\% higher than that of similar compositions with lightweight aggregates [7,8,11].

\section{Conclusions}

The construction industry is characterized by high material consumption, involving the consumption of a huge amount of natural raw materials and the waste of huge energy resources in production activities. In certain areas, there is the problem of a lack of binding 
materials, and, recently, the problem of the need for aggregates has arisen. There is a shortage of large and small aggregates in the industry, which requires the development of new effective technologies in the field of environmental materials science.

With the rational use of substandard and technogenic raw materials, the volumes of industrial waste dumps and fine sands can be reduced, as these occupy significant areas and negatively affect the environmental situation of the adjacent territories. The building materials industry, by absorbing a huge amount of waste, can have a significant positive impact on the economy of a region as a whole, while reducing the harmful impact of the industrial load on the environment. The developments and principles of this research could help reduce the negative impact of these regions on the ecological state of the entire planet.

Expansion of the use of substandard raw materials and man-made waste as secondary raw materials can serve as one of the most cardinal directions in the creation of waste-free processes that ensure the most rational use of natural resources and reduce the negative impact on the environmental situation.

Author Contributions: Conceptualization, L.Z.; Data curation, V.L., R.F. and M.K.; Funding acquisition, V.R.; Investigation, R.L.; Project administration, N.V.; Writing—original draft, V.L., L.Z., V.R., R.L., R.F., N.V. and M.K. All authors have read and agreed to the published version of the manuscript.

Funding: The research was partially funded by the Ministry of Science and Higher Education of the Russian Federation as part of the World-Class Research Center program Advanced Digital Technologies (contract No. 075-15-2020-934 dated 17.11.2020).

Institutional Review Board Statement: Not applicable.

Informed Consent Statement: Not applicable.

Data Availability Statement: Not applicable.

Conflicts of Interest: The authors declare no conflict of interest.

\section{References}

1. Cabrera-Covarrubias, F.; Gómez-Soberón, J.; Almaral-Sánchez, J.; Arredondo-Rea, S.; Gómez-Soberón, M.; Corral-Higuera, R. An Experimental Study of Mortars with Recycled Ceramic Aggregates: Deduction and Prediction of the Stress-Strain. Materials 2016, 9, 1029. [CrossRef]

2. Borek, K.; Czapik, P.; Dachowski, R. Recycled Glass as a Substitute for Quartz Sand in Silicate Products. Materials 2020, 13, 1030. [CrossRef]

3. Sadowska-Buraczewska, B.; Barnat-Hunek, D.; Szafraniec, M. Influence of Recycled High-Performance Aggregate on Deformation and Load-Carrying Capacity of Reinforced Concrete Beams. Materials 2020, 13, 186. [CrossRef]

4. Zagorodnyuk, L.H.; Koryakina, A.A.; Sevostyanova, K.I.; Khaheleva, A.A. Heat Insulating Composite Mixtures with Technogenic Materials. J. Phys. Conf. Ser. 2018, 1066, 012011. [CrossRef]

5. Yüksel, I.; Genç, A. Properties of concrete containing nonground ash and slag as fine aggregate. ACI Mater. J. 2007, 104, 397-403.

6. Gnanasundar, V.M.; Suvetha, S.; Preethy, S. Replacement of River Sand with Sea Sand and Granite Granules. In AIP Conference Proceedings; AIP Publishing LLC: Tamilnadu, India, 2019; p. 020011.

7. Tchamdjou, W.H.J.; Grigoletto, S.; Michel, F.; Courard, L.; Abidi, M.L.; Cherradi, T. An investigation on the use of coarse volcanic scoria as sand in Portland cement mortar. Case Stud. Constr. Mater. 2017, 7, 191-206. [CrossRef]

8. Mavroulidou, M. Mechanical Properties and Durability of Concrete with Water Cooled Copper Slag Aggregate. Waste Biomass Valor 2017, 8, 1841-1854. [CrossRef]

9. Deepti; Bansal, R. Review on Various Edge Detection Techniques. Int. J. Sci. Res. Dev. 2015, 3, $842-845$.

10. Xiao, Y.; Tutumluer, E.; Qian, Y.; Siekmeier, J.A. Gradation Effects Influencing Mechanical Properties of Aggregate Base-Granular Subbase Materials in Minnesota. Transp. Res. Rec. 2012, 2267, 14-26. [CrossRef]

11. Zagorodnyuk, L.H.; Ryzhikh, V.D.; Sumskoy, D.A.; Sinebok, D.A. Composite Binders Based on Dust of Electric Filters. In Innovations and Technologies in Construction; Klyuev, S.V., Lesovik, V.S., Vatin, N.I., Eds.; Lecture Notes in Civil Engineering; Springer International Publishing: Cham, Switzerland, 2021; Volume 95, pp. 253-259, ISBN 978-3-030-54651-9.

12. Shapovalov, N.A.; Zagorodnyuk, L.K.; Shchekina, A.Y.; Gorodov, A.I. Modified binders on the basis of flotation tailings. IOP Conf. Ser. Mater. Sci. Eng. 2018, 327, 032050. [CrossRef]

13. Palovčík, J.; Opravil, T.; Novotný, R.; Másilko, J. Application of brick grind dust in systems based on Portland cement. IOP Conf. Ser. Mater. Sci. Eng. 2018, 379, 012002. [CrossRef] 
14. Coppola, L.; Bellezze, T.; Belli, A.; Bignozzi, M.C.; Bolzoni, F.; Brenna, A.; Cabrini, M.; Candamano, S.; Cappai, M.; Caputo, D.; et al. Binders alternative to Portland cement and waste management for sustainable construction-Part 2. J. Appl. Biomater. Funct. Mater. 2018, 16, 207-221. [CrossRef] [PubMed]

15. Behiry, A.E.A.E.M. Utilization of cement treated recycled concrete aggregates as base or subbase layer in Egypt. Ain Shams Eng. J. 2013, 4, 661-673. [CrossRef]

16. Courard, L.; Rondeux, M.; Zhao, Z.; Michel, F. Use of Recycled Fine Aggregates from C\&DW for Unbound Road Sub-Base. Materials 2020, 13, 2994. [CrossRef]

17. Zagorodnuk, L.K.; Lesovik, V.S.; Elistratkin, M.Y.; Sumskoy, D.A.; Makhortov, D.S.; Zolotykh, S.V. New methods for manufacturing composite materials. J. Phys. Conf. Ser. 2019, 1353, 012060. [CrossRef]

18. Nikonorov, V.M.; Nikonorov, V.V. One of the approaches to the concrete strength mathematical model. IOP Conf. Ser. Mater. Sci. Eng. 2020, 945, 012014. [CrossRef]

19. Kobayashi, H. Mathematical Models in First-Principles Calculations for Materials Science. In A Mathematical Approach to Research Problems of Science and Technology; Nishii, R., Ei, S., Koiso, M., Ochiai, H., Okada, K., Saito, S., Shirai, T., Eds.; Mathematics for Industry; Springer: Tokyo, Japan, 2014; Volume 5, pp. 467-480, ISBN 978-4-431-55059-4.

20. Thomas, C.; Cimentada, A.I.; Cantero, B.; Sáez del Bosque, I.F.; Polanco, J.A. Industrial Low-Clinker Precast Elements Using Recycled Aggregates. Appl. Sci. 2020, 10, 6655. [CrossRef]

21. Cantero, B.; Bravo, M.; de Brito, J.; Sáez del Bosque, I.F.; Medina, C. Thermal Performance of Concrete with Recycled Concrete Powder as Partial Cement Replacement and Recycled CDW Aggregate. Appl. Sci. 2020, 10, 4540. [CrossRef]

22. Aljasimee, D.H.; Dhaheer, M.S.A. Fresh and hardened properties of self-compacting concrete incorporating PVA-treated recycled aggregate. Mater. Sci. Eng. 2020, 12, 012103. [CrossRef]

23. Montanari, D.; Agostini, A.; Bonini, M.; Corti, G.; Ventisette, C. The Use of Empirical Methods for Testing Granular Materials in Analogue Modelling. Materials 2017, 10, 635. [CrossRef]

24. Popov, M.; Zakrevskaya, L.; Vaganov, V.; Hempel, S.; Mechtcherine, V. Performance of Lightweight Concrete based on Granulated Foamglass. IOP Conf. Ser. Mater. Sci. Eng. 2015, 96, 012017. [CrossRef]

25. Pichór, W.; Kamiński, A.; Szołdra, P.; Frąc, M. Lightweight Cement Mortars with Granulated Foam Glass and Waste Perlite Addition. Adv. Civ. Eng. 2019, 2019, 1-9. [CrossRef]

26. Miller, S.A. The role of cement service-life on the efficient use of resources. Environ. Res. Lett. 2020, 15, 024004. [CrossRef]

27. Zagorodnyuk, L.K.; Lesovik, V.S.; Sumskoy, D.A.; Elistratkin, M.Y.; Makhortov, D.S. Peculiarities of binding composition production in vortex jet mill. IOP Conf. Ser. Mater. Sci. Eng. 2018, 327, 042128. [CrossRef]

28. Romanovich, A.A.; Amini, E.; Romanovich, M.A. Improving the efficiency of the material grinding process. IOP Conf. Ser. Mater. Sci. Eng. 2020, 945, 012060. [CrossRef]

29. Romanovich, A.A.; Romanovich, M.A.; Belov, A.I.; Chekhovskoy, E.I. Energy-saving technology of obtaining composite binders using technogenic wastes. J. Phys. Conf. Ser. 2018, 1118, 012035. [CrossRef]

30. Yin, Z.; Peng, Y.; Zhu, Z.; Yu, Z.; Li, T. Impact Load Behavior between Different Charge and Lifter in a Laboratory-Scale Mill. Materials 2017, 10, 882. [CrossRef]

31. Usanova, K.; Barabanshchikov, Y.G. Cold-bonded fly ash aggregate concrete. Mag. Civ. Eng. 2020, 95, 104-118. [CrossRef]

32. Korsun, V.; Vatin, N.; Korsun, A.; Nemova, D. Physical-mechanical properties of the modified fine-grained concrete subjected to thermal effects up to $200{ }^{\circ} \mathrm{C}$. Appl. Mech. Mater. 2014, 633-634. [CrossRef]

33. Fediuk, R.S.; Lesovik, V.S.; Liseitsev, Y.L.; Timokhin, R.A.; Bituyev, A.V.; Zaiakhanov, M.Y.; Mochalov, A.V. Composite binders for concretes with improved shock resistance. Mag. Civ. Eng. 2019, 85, 28-38. [CrossRef]

34. Ayzenshtadt, A.; Lesovik, V.; Frolova, M.; Tutygin, A.; Danilov, V. Nanostructured wood mineral composite. Procedia Eng. 2015, 117, 45-51. [CrossRef]

35. Fediuk, R.; Pak, A.; Kuzmin, D. Fine-Grained Concrete of Composite Binder. IOP Conf. Ser. Mater. Sci. Eng. 2017, 262, 012025. [CrossRef]

36. Barabanshchikov, Y.; Fedorenko, I.; Kostyrya, S.; Usanova, K. Cold-Bonded Fly Ash Lightweight Aggregate Concretes with Low Thermal Transmittance: Review. Adv. Intell. Syst. Comput. 2019, 983, 858-866. [CrossRef]

37. Usanova, K. Properties of Cold-Bonded Fly Ash Lightweight Aggregate Concretes. Lect. Notes Civ. Eng. 2020, 70, 507-516. [CrossRef]

38. Zagorodnyuk, L.K.; Lesovik, V.S.; Sumskoy, D.A. Thermal insulation solutions of the reduced density. Constr. Mater. Prod. 2018, 1, 40-50.

39. Fediuk, R.; Yushin, A. Composite binders for concrete with reduced permeability. IOP Conf. Ser. Mater. Sci. Eng. 2016, $116,012021$. [CrossRef]

40. Fediuk, R. Reducing permeability of fiber concrete using composite binders. Spec. Top. Rev. Porous Media 2018, 9, 79-89. [CrossRef]

41. Haridharan, M.K.; Matheswaran, S.; Murali, G.; Abid, S.R.; Fediuk, R.; Mugahed Amran, Y.H.; Abdelgader, H.S. Impact response of two-layered grouted aggregate fibrous concrete composite under falling mass impact. Constr. Build. Mater. 2020, $263,120628$. [CrossRef] 